\title{
UNA APROXIMACIÓN A LA PARTICIPACIÓN \\ DE LAS MUJERES EN EL COMERCIO DE TENERIFE \\ EN EL SIGLO XVIII. LA COMPAÑÍA BINI Y DUGI*
}

\author{
Ana Rosa Pérez Álvarez ${ }^{* *}$ \\ María Eugenia Monzón Perdomo*** \\ Universidad de La Laguna
}

\section{RESUMEN}

El propósito de este trabajo es comenzar a desentrañar el papel de las mujeres en las actividades mercantiles desarrolladas en Tenerife en la segunda mitad del siglo Xviri. Actualmente ya podemos afirmar que en el Antiguo Régimen las féminas monopolizaron los intercambios en los mercados locales, encargados del abastecimiento de los productos básicos de consumo. El análisis detallado de las compañías comerciales fundadas en esa centuria pone de manifiesto que las mujeres colaboraron activamente en esta escala de las transacciones. Ocultas tras los denominados «hombres del comercio» descubrimos auténticas «mercaderas» que actuaban, directa o indirectamente, en los asuntos económicos que concernían a la familia.

Palabras Clave: comercio, compañías comerciales, género, Canarias, siglo XviII.

\section{AN APPROACH TO THE PARTICIPATION OF WOMEN IN TENERIFE TRADE IN THE $18^{\mathrm{TH}}$ CENTURY. THE COMPANY BINI AND DUGI}

\section{Abstract}

The purpose of this work is to begin to unravel the role of women in commercial activities, developed in Tenerife in the second half of the $18^{\text {th }}$ century. At present, we can already affirm that in the Old Regime the females monopolized the exchanges in the local markets, in charge of the supply of the basic consumption products. The detailed analysis of commercial companies, founded in that century, shows that women actively collaborated in this scale of transactions. Hidden behind the so-called "men of commerce" we discovered authentic "women merchants" who acted, directly or indirectly, in the economic matters that concerned the family.

Keywords: Commerce, Commercial Companies, Gender, Canary Islands, $18^{\text {th }}$ Century. 
En el siglo xviıI Santa Cruz de Tenerife era una importante plaza comercial con un puerto muy activo, que había atraído a numerosas colonias de negociantes extranjeros desde el siglo xvi. Convertida en una ciudad dedicada preferentemente a los intercambios, se fue afianzando como centro de distribución de mercancías que procedían del extranjero, no sólo hacia el interior de la isla sino también al resto del Archipiélago.

Las actividades mercantiles en sus diferentes escalas: local, interinsular, nacional e internacional, atendieron, en primer lugar, al abastecimiento de la población de las necesidades básicas -alimentos, vestidos y herramientas de trabajo-. Inicialmente éstas procedían de la producción local, pero las tempranas relaciones del Archipiélago con el exterior favorecieron la circulación de mercancías venidas de otros lugares y la creación de instrumentos que garantizaran la salida de las producciones canarias hacia el exterior.

Gran parte de estos negocios estuvieron en manos de colonias de mercaderes procedentes de diversos enclaves europeos. Como afirma Francisco Fajardo, estos extranjeros afincados en las islas acabaron formando comunidades dedicadas preferentemente al comercio; ellos fueron los principales responsables de la incorporación de Canarias a los grandes circuitos mercantiles europeos y transoceánicos ${ }^{1}$.

Estos negociantes fueron recalando progresivamente en las islas a lo largo de la Edad Moderna. Inicialmente acudieron genoveses y portugueses, a los que se fueron sumando efectivos procedentes de Flandes, Francia, Inglaterra y de diversas

* Abreviaturas utilizadas: AHPSCT $=$ Archivo Histórico Provincial de Santa Cruz de Tenerife; APICSCT = Archivo Parroquial de la Iglesia de la Concepción de Santa Cruz de Tenerife; P.N. = Protocolo Notarial.

** Investigadora vinculada a la Universidad de La Laguna. anaperalv@gmail.com.

*** Profesora titular de Historia Moderna. Instituto Universitario de las Mujeres de la Universidad de La Laguna. memonzon@ull.edu.es.

1 Fajardo Spínola, Francisco: «Una comunidad mercantil atlántica: los ingleses en las Islas Canarias», Anuario de Estudios Atlánticos, n. ${ }^{\circ} 59$ (2013), p. 385. 
áreas de Italia ${ }^{2}$. A ellos se uniría, en la centuria ilustrada, una fuerte afluencia de irlandeses ${ }^{3}$.

La tendencia de la mayor parte de los comerciantes llegados a Canarias fue el asentamiento definitivo ${ }^{4}$. La vecindad podía obtenerse a través de tres fórmulas perfectamente establecidas: por nacimiento, solicitud de admisión y pago y, sobre todo, por matrimonio. Sin lugar a dudas, ésta última sería la fórmula preferida por las colonias extranjeras desde los primeros años de la conquista 5 .

En consecuencia, los enlaces familiares se fueron afianzando y permitieron desempeñar las actividades mercantiles con todos los derechos que la vecindad otorgaba. Un ejemplo de tal comportamiento lo representa la comunidad flamenca, instalada de manera temprana en el entorno insular, que, como es sabido, buscaban

2 Algunas referencias bibliográficas sobre el asentamiento de los comerciantes extranjeros en Canarias: Arbelo García, Adolfo: Los Massieu Monteverde de La Palma: Familia, Relaciones Sociales y Poder Politico en Canarias durante el Siglo XVIII, Santa Cruz de Tenerife, 2009; Bello León, Juan Manuel y González. Marrero, M. ${ }^{a}$ del Cristo: "Los “otros extranjeros": catalanes, flamencos, franceses e ingleses en la sociedad canaria de los siglos XV y XVI, (1. ${ }^{a}$ parte), Revista de Historia Canaria, vol. 179 (1997), pp. 11-71; Bello León, Juan Manuel y González Marrero, M. ${ }^{a}$ del Cristo: "Los "otros extranjeros" catalanes, flamencos, franceses e ingleses en la sociedad canaria de los siglos xv y xvi (Continuación del artículo publicado en el n. ${ }^{\circ} 179$ de la Revista de Historia Canaria)», Revista de Historia Canaria, vol. 180 (1998), pp. 13-55; Bonnet y Reveron, Buenaventura: «Lugo y los mercaderes genoveses», Revista de Historia Canaria, n. ${ }^{\circ}$ 90-91 (1950), pp. 248-250; Bordes GARCíA, José: «La participación de los mercaderes florentinos en el comercio (siglos XV-XVI), en $\mathrm{La}$ Torre, Homenaje a Emilio Alfaro Hardisson, La Laguna, 2005, pp. 145-159; Brito GonZÁLEz, Alexis: "Matricula de extranjeros en Canarias durante la segunda mitad del siglo XviII", Anuario de Estudios Atlánticos, n. ${ }^{\circ} 45$ (1999), pp. 219-260; Brito GonzÁlez, Alexis: «Un ejemplo de integración social: el flamenco Nicolás Martínez de Escobar», Vegueta, n. 4 (1999), pp. 153-168; Brito GonzÁlez, Alexis: Los extranjeros en las canarias Orientales en el siglo XVI, Las Palmas de Gran Canaria, 2002; Brito GonzÁlez, Alexis: "Naturalizaciones de extranjeros en Canarias en el Antiguo Régimen», en XV Coloquio de Historia Canario-Americana, 2002, Las Palmas de Gran Canaria, 2004, pp. 274-287; Chanel-Tisseau des Escotais, Josette: «Le consulat de France aux Canaries, au XVIII ${ }^{\mathrm{e}}$ siècle: une affaire de families les Porlier et les Casalon", Pouvoirs de la famille, familles de pouvoir, Coloquio Internacional de FRA.M.ESPA, 2000, Toulouse, 2005, pp. 227-238; Iglesias Hernández, M. ${ }^{a}$ Luisa: Los extranjeros en Gran Canaria. Primer tercio del siglo XVIII, Las Palmas de Gran Canaria, 1985; Lobo Cabrera, Manuel y Torres Santana, Elisa: «Los extranjeros en Canarias durante el Antiguo Régimen», I Coloquio Internacional "Los extranjeros en la España moderna», Málaga, 2003, pp. 79-97; Lово Cabrera, Manuel: El comercio canario europeo bajo Felipe II, Canarias y Madeira, 1988; Отте, Enrique, «Los Sopranis y los Lugo», en II Coloquio de Historia Canario-Americana, t. I, 1977, Las Palmas de Gran Canaria, 1979, pp. 239-260; Paz SÁnChez, Manuel de: Flandes y Canarias. Nuestros orígenes nórdicos, Santa Cruz de Tenerife [vol. III], 2004.

${ }^{3}$ Fajardo Spínola, Francisco, opus cit., 2013, p. 385. Guimerá Ravina, Agustín: Burguesia extranjera y comercio atlántico. La empresa comercial irlandesa en Canarias 1703-1771, Santa Cruz de Tenerife, 1985.

${ }^{4}$ Monzón Perdomo, María Eugenia y Pérez Álvarez, Ana Rosa: «Comprar y vender en Canarias a fines del Antiguo Régimen. Aproximación al comercio al por menor en Santa Cruz de Tenerife (1750-1818)», en Henarejos López, Juan Francisco e Irigoyen López, Antonio (eds.): Escenarios de familia: trayectorias, estrategias y pautas culturales, siglos XVI-XX, Murcia, 2017, p. 244.

5 VIÑa Brito, Ana: «Los flamencos en Canarias en el siglo XVI ¿Una comunidad extranjera? Especificidades en la Isla de la Palma», Revista de Historia Canaria, n. ${ }^{\circ} 161$ (2012), p. 167. 
emparentarse con mujeres naturales de las islas con una posición económica desahogada y vinculada a las redes comerciales isleñas ${ }^{6}$.

Uno de los mecanismos que ayudaron a impulsar los intercambios mercantiles, desde los primeros tiempos tras la conquista, fue la constitución de agrupaciones de comerciantes. Como señala Lobo Cabrera, la manera más frecuente de acometer los peligros que entrañaba el comercio en el Atlántico fue compartir los riesgos utilizando la fórmula de las compañías de comercio, con las que podían dar el verdadero alcance de los tráficos comerciales que necesitaban o que querían desarrollar.

Como apuntábamos anteriormente, el puerto de Santa Cruz de Tenerife, por su especialización en este tipo de intercambios, fue testigo del surgimiento de muchas compañías encargadas de esta labor.

Sin lugar a dudas, la formalización de estas entidades respondía a unos intereses económicos compartidos ahora bien, no es menos cierto que la mayor parte de estos instrumentos fueron concebidos en el entorno de la familia. La principal estrategia desplegada por los hombres de negocio fue unir los intereses económicos con los sólidos lazos del parentesco o, dicho de otro modo, para los mercaderes el matrimonio consistía en una unión similar a la que establecían por motivos mercantiles con otros individuos ${ }^{8}$.

Siguiendo la misma línea argumentativa, si los enlaces matrimoniales eran un factor determinante en la creación del espacio económico también lo debería ser el papel que desempeñaban las mujeres en las empresas creadas por sus maridos, o fundadas por sus padres y/o hermanos y continuadas por sus cónyuges.

La metodología empleada en el presente trabajo debe estar directamente relacionada con el análisis de género. Entendiendo el concepto de género como «... la construcción de formas culturales consideradas como apropiadas para el comportamiento de individuos de sexo masculino o femenino...»".

Los estudios realizados desde este enfoque han confirmado, como señala Marcela Aguirrezabala, que la información sobre los hombres es también información sobre las mujeres ${ }^{10}$, y en este sentido es lícito, y necesario, interrogarnos sobre la intervención de las mujeres en las actividades laborales del conjunto de la familia:

${ }^{6}$ Gómez Gómez, Miguel Ángel: «Endogamia, comercio y poder. Consideraciones en torno a la presencia flamenca en Tenerife (1600-1750)", en PAZ SáncheZ, de Manuel (dir.): Flandes y Canarias. Nuestros orígenes nórdicos, Santa Cruz de Tenerife, [tomo II], 2004, p. 44.

7 Lobo Cabrera, Manuel: «Comercio y burguesía mercantil en Canarias en la Edad Moderna", en Lobo Cabrera, Manuel y Suárez Grimón, Vicente (eds.): El comercio en el Antiguo Régimen. III Reunión Científica de la Asociación Española de Historia Moderna, Las Palmas de Gran Canaria [vol. II], 1994, p. 141.

${ }^{8}$ Fernández Pérez, Paloma: El rostro familiar de la metrópoli. Redes de parentesco y lazos mercantiles en Cádiz, 1700-1812, Madrid, 1997, p. 127.

9 Ramos Escandón, Carmen: «El concepto de 'Género' y su utilidad para el análisis histórico», en La Aljaba. Revista de Estudios de la Mujer, 2. Época, vol. 2 (1997), pp. 13-32.

10 Aguirrezabala, Marcela: «Mujeres casadas en los negocios y el comercio ultramarino entre el Río de la Plata y la Península a fines del siglo xviII», Anuario de Estudios Americanos, tomo LVIII, 1, (2001), p. 116. 
¿qué papel jugaron las mujeres en estos acuerdos económicos? ¿Participaron en la toma de decisiones o asumieron sin contestación los deseos paternos? ¿Se implicaron en las actividades comerciales que se derivaban de su nueva situación familiar? ¿Aprendían desde pequeñas viendo a sus familiares el trabajo que realizaban, casi de forma imperceptible, y poco a poco los iban sustituyendo en determinadas actividades?

\section{LAS MUJERES Y EL TRABAJO}

En la actualidad está fuera de toda duda la contribución de las féminas al desarrollo de la economía familiar en todos los tiempos, y, aunque poseemos mayor información sobre aquéllas que lo hicieron como asalariadas, no debemos perder de vista, como afirma Monserrat Carbonell, que en las sociedades preindustriales el trabajo se llevaba a término en el entorno doméstico en una conjunción de tareas productivas, reproductivas y derivadas del consumo ${ }^{11}$.

Y es que la casa, en el Antiguo Régimen, ha sido considerada como la unidad de producción, en la que todos sus miembros participaban en el conjunto de las tareas que permitían la subsistencia. La sociedad patriarcal, como sostiene Margarita Ortega, vino definida por un modelo de familia cooperante donde las labores desempeñadas por las féminas del hogar se convirtieron en "trabajo invisible»" ${ }^{12}$.

La falta de reconocimiento histórico de la participación de las mujeres en las labores productivas parte, en gran medida, de la llamada teoría de las esferas separadas, predominante en el siglo XIx. Esta tesis se sustentaba en una rígida separación entre las labores desempeñadas por los hombres y las llevadas a cabo por las mujeres: mientras que los varones actuaban en la esfera pública ellas permanecían recluidas en el espacio privado alejadas de las actividades extradomésticas ${ }^{13}$.

En honor a la verdad hemos de decir que esta interpretación ha sido cuestionada desde la década de los 90 del siglo pasado por la Historia de las Mujeres. Destacadas autoras ${ }^{14}$ insisten en señalar que el error ha estado en la confusión generalizada entre la teoría y la realidad ${ }^{15}$. Cabe añadir que la existencia de un discurso hegemónico sobre las funciones propias de las mujeres no quiere decir que en la

11 Carbonell, Monserrat: «Trabajo femenino y economías familiares», en Morant, Isabel (dir.): Historia de las mujeres en España y América Latina, Madrid, [tomo II], 2005, p. 244.

12 Ortega López, Margarita: «Las trabajadoras madrileńas del pueblo llano durante el siglo XVIII", Arenal, vol. 13, n. ${ }^{\circ} 2$ (2006), p. 317.

13 Aguirrezabala, Marcela: «Les dones del comerç ultramarí. Riu de la Plata, 1776-1810», Recerques, n. ${ }^{\circ} 56$ (2008), p. 137.

${ }^{14}$ Notables historiadoras han hecho importantes aportaciones en este ámbito: Davis, Natalie Zemon; Hufton, Olwen; Scott, Joan; Tilli, Louise; Weisner, Merry, etc.

15 Solá Parera, Àngels: «Las mujeres como partícipes, usufructuarias y propietarias de negocios en la Barcelona de los siglos XVIII y XIX según la documentación notarial», Historia Contemporánea, n. ${ }^{\circ} 44,(2011)$, p. 111. 
práctica se observara, unas veces por la imposibilidad de hacerlo y en otras porque la cultura laboral del sector no sólo lo permitía sino que lo facilitaba ${ }^{16}$.

El trabajo de las mujeres, por lo tanto, se ha caracterizado por atender a múltiples facetas de la vida: producción y reproducción unidas en el mismo escenario doméstico.

Desde la Edad Media en los núcleos urbanos ellas se empleaban principalmente en el suministro de los productos de primera necesidad, a través de la venta en los mercados, en tiendas - ubicadas en sus propios domicilios- o de manera ambulante ${ }^{17}$.

La presencia de locales urbanos regentados por mujeres debió ser una realidad incontestable en la Europa moderna, de manera que el abastecimiento de las ciudades no hubiera funcionado sin el trabajo femenino ${ }^{18}$.

Los estudios realizados en el entorno del archipiélago canario corroboran esta afirmación. En las diferentes categorías del comercio en las islas: mercaderes encargados del comercio internacional, las lonjas, tiendas de mercería o simplemente tiendas y, por último, en la venta ambulante, la mano de obra femenina se concentraba en las escalas inferiores ${ }^{19}$.

En las ventas al por menor, las mujeres se perfilaban como agentes controladores de la distribución de mercancías y servicios, y fueron consideradas como las verdaderas dirigentes del comercio local ${ }^{20}$. Un ejemplo significativo se cifra en el porcentaje de féminas que consiguieron licencia de las autoridades tinerfeñas para abrir una tienda en el territorio insular: en la segunda mitad del siglo XVII el 96\% del total de lugares de venta autorizados estaba regentado por mujeres ${ }^{21}$.

16 Solá Parera, Àngels: «Las mujeres como productoras autónomas en el medio urbano (siglos XIV al XIX)", en Borderías, Cristina, (ed.): La historia de las mujeres: perspectivas actuales, Barcelona, 2009, p. 254. 2012, p. 211.

${ }_{17}$ Ramiro Moya, Francisco: Mujeres y trabajo en la Zaragoza del siglo XVIII, Zaragoza,

${ }^{18}$ Lopes, María Antonia: «Mulheres e trabalho em Coimbra (Portugal) no século xvinI e Inícios do XiX», en Iglesias Rodríguez, Juan José, Pérez García, Rafael y Fernández Cháves, Manuel (eds.): Comercio y Cultura en la Edad Moderna, Sevilla, 2015, p. 1773 (edición en CD-ROM).

19 Monzón Perdomo, María Eugenia y Pérez Álvarez, Ana Rosa: opus cit., 2017, pp. 243-255; Monzón Perdomo, María Eugenia: «Género y vida cotidiana. Oficios femeninos en las ciudades canarias en el Antiguo Régimen", en Franco Rubio, Gloria (ed.): La vida de cada día. Rituales, costumbres y rutinas cotidianas en la España Moderna, Madrid, 2012, pp. 273-298; PÉrez Álvarez, Ana Rosa: «Vendederas o vendedoras de cesto. Las vendederas ambulantes de Tenerife en los textos de la Real Sociedad Económica de Amigos del País de Tenerife (1783)», I y II, periódico El Día. Suplemento de La Prensa, 9 y 16 de abril (2005).

${ }^{20}$ Tovar Pulido, Raquel: «Pobres, hacendadas, comerciantes y otros oficios: economías femeninas y estructura de la familia entre las viudas de finales del Antiguo Régimen (Trujillo)», Studia Histórica, Historia Moderna, vol. 39, n. ${ }^{\circ} 2$ (2017), p. 413.

${ }^{21}$ Monzón Perdomo, María Eugenia: «Las mujeres en los espacios públicos. El abastecimiento del mercado interno como experiencia laboral para las mujeres del Antiguo Régimen en Tenerife», Revista de Historia Canaria, n. ${ }^{\circ} 191$ (2009), p. 141. 
Hay que hacer notar que este predominio, casi monopolio, femenino va decayendo a medida que aumenta la importancia económica de las transacciones: cuanta más inversión de capital requiere el negocio, menor es la visibilidad de las mujeres en ellos.

En consecuencia son escasas las informaciones que tenemos sobre la participación de las féminas en el comercio a gran escala. Sin embargo, esta falta de referencias directas en ningún caso confirma su exclusión de esta profesión y para desentrańarla hay que acudir a testamentos, codicilos y documentos de índole económica, en los que se encuentran algunos testimonios que nos han permitido acercarnos al papel que desarrollaban las mujeres en las empresas familiares.

\section{COMPAÑÍAS COMERCIALES. LA COMPANIÍA DE BINI Y DUGI}

La creación de una compañía comercial solía estar directamente relacionada con el devenir de la actividad mercantil de varios mercaderes. Tomaremos como ejemplo la compañía creada por D. Antonio Bini y D. Francisco Dugi en la segunda mitad del siglo XVIII. Lo que inicialmente fue la unión comercial de dos socios, ligados por el paisanaje, ya que ambos procedían de la misma localidad italiana, se fue consolidando en el entorno de una familia asentada en el puerto de Santa Cruz.

La familia formada por D. Dionisio Ryan y Dña. Bárbara Ligero, él procedente de Irlanda ${ }^{22}$ y ella vecina de Santa Cruz ${ }^{23}$, tuvo una amplia descendencia: ocho hijos - dos varones y seis mujeres-. El futuro de tan extensa prole fue diverso, unos optaron por la vida religiosa -sor María de Santo Domingo de Guzmán Ryan, monja clarisa de La Laguna, y Fray José Ryan-, el segundo de los hijos partió hacia América donde contrajo matrimonio. El resto de las mujeres de la familia, a excepción de Dńa. Brígida Ryan Ligero, que se mantuvo en estado honesto y permaneció al lado de su madre hasta su fallecimiento, contrajeron matrimonio.

Las alianzas concertadas por los Ryan fueron las habituales entre las familias dedicadas al comercio en el siglo XviIr. Las cuatro hijas: Dña. Juana, Dña. Teresa, Dña. Tomasa y Dña. Bárbara Antonia, tomaron estado con hombres procedentes del exterior: D. Antonio Bini, D. Francisco Dugi, ambos arribaron a Santa Cruz en 1760, D. Jacome Busse, localizado en la ciudad desde 1752, y D. Juan Bautista Nozzolini, presente desde 1751, respectivamente. Por consiguiente, el hilo conductor de estas cuatro ramas del árbol genealógico sería el apellido Ryan.

El diseńo de la estrategia matrimonial, en cualquier caso, debía recaer en el cabeza de familia, rol desempeñado por los varones de más edad de la estirpe. No

${ }^{22}$ Desconocemos la fecha de llegada de D. Dionisio Ryan a Tenerife y cuándo tuvo lugar el enlace con Dña. Bárbara Ligero.

${ }^{23}$ Dńa. Bárbara era vecina de Santa Cruz, pero por los apellidos de su padre, D. Nicolás Ligero Papachin y Escalier, y de su madre, Dña. Josefa Murrieta, intuimos que procedían del exterior. 
obstante, no sería el padre de las jóvenes, D. Dionisio Ryan, el encargado de llevar a cabo la concertación de los enlaces, pues había fallecido en el naufragio de un barco que venía de Campeche sobre $1756^{24}$. En último extremo, sería Dña. Bárbara Ligero, en ausencia de su esposo, la autorizada para decidir el futuro matrimonial de sus hijas ${ }^{25}$ (ver árbol genealógico, fig. 1).

Aunque no contamos con datos suficientes que lo avalen, intuimos que la familia Ryan había conseguido un cierto arraigo en los negocios santacruceros y gozaba de una posición desahogada, a juzgar por los bienes declarados por Dña. Bárbara $^{26}$. Este factor pudo constituir un acicate para aquellos mercaderes noveles que pretendían hacerse un hueco en la élite de la sociedad del momento. Como señala Juan Manuel Bartolomé, en relación con el entorno de León en el siglo XVIII, para los comerciantes advenedizos el matrimonio con jóvenes locales procedentes de la esfera mercantil era una oportunidad que no podían dejar pasar por alto ${ }^{27}$. La verdad es que esta pauta se repite de manera sistemática en todas las ciudades del Antiguo Régimen. En La Rioja, como apunta Fernando Hidalgo, los propios comerciantes aconsejaban a sus hijas, a través de sus notas testamentarias, que se casaran con comerciantes y no con personas procedentes de otros negocios, ante el temor de que disiparan sus dotes ${ }^{28}$.

Estas prácticas se trasladaron al continente americano, puesto que tanto en la ciudad de Buenos Aires, estudiada por Susan Socolon ${ }^{29}$, como en el entorno mexicano, conocido por Paloma Fernández ${ }^{30}$, las hijas de los comerciantes estable-

${ }^{24}$ En su testamento Dña. Bárbara dice que su marido había fallecido unos 20 años antes (AHPSCT, P.N. 1.292, fols. 244v.-249v., 1776), pero hemos revisado los libros de entierros de la iglesia de la Concepción y no se realizó ningún oficio por su alma entre el 01/01/1755 y el 02/04/1758 (APICSCT, Libros VIII y IX de entierros).

${ }^{25}$ La primera en desposarse fue Dña. Bárbara Antonia, que lo hizo en 1758 con D. Juan Bautista Nozzolini, varios años después de la muerte de su padre, y con posterioridad formalizarían sus compromisos el resto de las hermanas: Dńa. Tomasa Ryan contrajo matrimonio con D. Jácome Busse en 1760, Dña. Teresa Ryan se casó con D. Francisco Dugi en 1766 y, por último, Dña. Juana Ryan enlazó con D. Antonio Bini en 1771 (APICSCT, Libros de matrimonios v, fol. 294r., 02/04/1758; vI, fol. 26r., 25/12/1760; vi, fol. 123r., 25/10/1766; y vi, fol. 195 r., 10/08/1771).

${ }^{26}$ AHPSCT, P.N. 1.292, fols. 244v.-249v., 1776.

27 Bartolomé Bartolomé, Juan Manuel: «Mujeres y negocios comerciales: el ejemplo de las familias leonesas (1700-1850)», en Iglesias Rodríguez, Juan José, Pérez García, Rafael y Fernández Cháves, Manuel (eds.): Comercio y Cultura en la Edad Moderna, Sevilla, 2015, p. 494 (edición en CD-ROM).

${ }^{28}$ Hidalgo Lerdo de Tejada, Fernando: «Redes familiares y comerciales en la comunidad riojana en el siglo Xviri. Primeros resultados», en Iglesias Rodríguez, Juan José, Pérez García, Rafael y Fernández Cháves, Manuel (eds.): Comercio y Cultura en la Edad Moderna, Sevilla, 2015, p. 520 (edición en CD-ROM).

29 Socolow, Susan: «Marriage, Birth, and Inheritance: The Merchants of Eighteenth-Century Buenos Aires», Hispanic American Historical Review, vol. 60/ n. 3 (1980), p. 391.

30 Fernández Pérez, Paloma y Sola-Corbacho, Juan Carlos: «Regional identity, family, and trade in Cadiz and Mexico city in the Eighteenth Century», Journal of Early of Modern History, vol. 8, n. ${ }^{\circ} 3-4$, (2004), p. 379. 


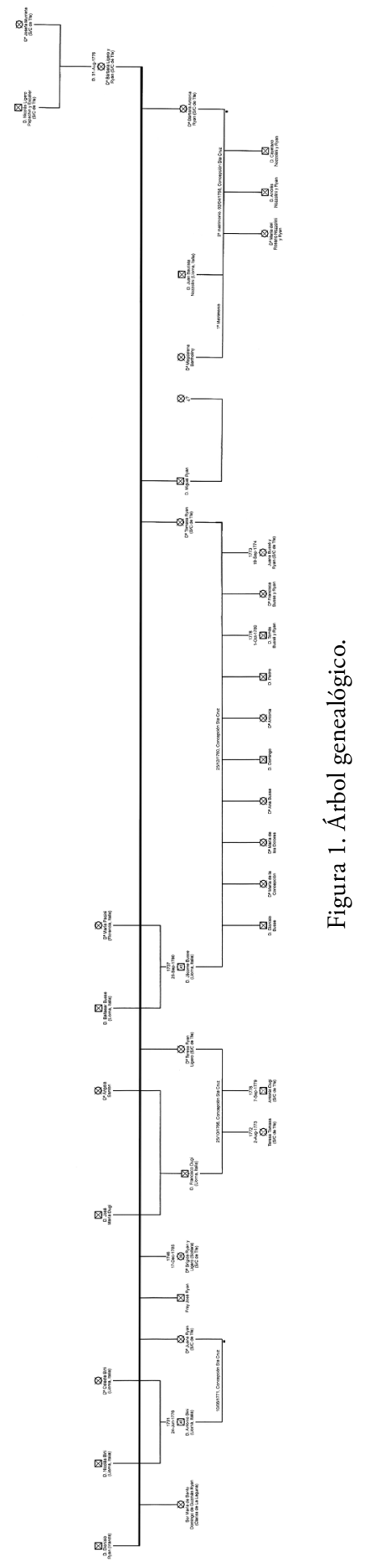


cidos en ambos territorios eligieron contraer matrimonio con hombres procedentes de la misma rama profesional que sus progenitores.

A modo de ver de Paloma Fernández el procedimiento habitual en la concertación de matrimonios presenta dos características principales: la exogamia familiar combinada con la endogamia profesional y geográfica, esto es, los enlaces se acordaban entre miembros de una misma comunidad profesional y de procedencia, pero fuera de la propia familia ${ }^{31}$.

En nuestro caso se cumplen esos dos parámetros: se trata de una exogamia familiar clara, mientras que en el terreno profesional y geográfico apunta a la endogamia. $\mathrm{Y}$ es que los cónyuges escogidos para las mujeres Ryan eran todos oriundos de la ciudad de Liorna ${ }^{32}$, en Italia. Como señala Alejandro Cioranescu, la afluencia de población procedente de Italia a la ciudad de Santa Cruz fue abundante desde el siglo XVI. Los primeros italianos en visitar el Archipiélago eran naturales de Génova y muchos de ellos terminaron asentándose definitivamente en las principales ciudades de las islas debido a su vinculación con el comercio ${ }^{33}$. Si bien es verdad que el tráfico canario con la ciudad de Génova se inicia de manera temprana, no es menos cierto que el enclave de Liorna podía haber mantenido contactos con los puertos canarios debido a su cercanía con la ciudad de Génova.

De ahí que no es de extrañar que tanto Bini como Dugi se establecieran en las islas desde mediados de la centuria. Su trayectoria profesional les había llevado a emprender negocios, documentados desde 1770, a través de diversas sociedades como la de Antonio Bini y Compañia ${ }^{34}$. Según los datos que conocemos, la asociación fue anterior a la formalización del vínculo familiar, pues D. Francisco Dugi contrajo matrimonio con Dña. Teresa Ryan en 1766 actuando como padrino D. Antonio Bini ${ }^{35}$. Por su parte, éste último formalizó su vínculo con Dña. Juana Ryan en 1771. A partir de este momento los lazos de parentesco unirían a los dos comerciantes a través de sus respectivos matrimonios.

Además, hay que destacar el papel jugado por los enlaces matrimoniales en una familia como la Ryan, donde la presencia de mujeres era destacada. La estrategia de progreso familiar establecida por Dńa. Bárbara Ligero Ryan radicaba en la elección de yerno. En la medida en que sus hijas no podían hacerse cargo abiertamente de los negocios de la familia la única opción era la de incorporar, mediante alianzas matrimoniales, a jóvenes y prometedores mercaderes que dieran continuidad a los negocios de la familia. Este fenómeno, conocido como "yernocracia» o poder de los yernos, ha sido estudiado por Paloma Fernández en el Cádiz del siglo XVIII ${ }^{36}$.

${ }^{31}$ Fernández Pérez, Paloma: opus cit., 1997, p. 164.

${ }_{32}$ Nombre espańolizado de la actual Liborno, ciudad costera situada en la Toscana italiana.

33 Cioranescu, Alejandro: Historia de Santa Cruz, t. II, Santa Cruz de Tenerife, 1977, p. 101-102.

${ }^{34}$ AHPSCT, P.N. 1609, fols. 118r.-120r., 1776.

35 APICSCT, Libro de matrimonios vi, fol. 123r., 25/10/1766.

36 Fernández Pérez, Paloma: opus cit., 1997, p. 162. 
En efecto, los yernos de Dña. Bárbara a través de la Compañia Bini y Dugi desplegaron un intenso comercio entre los años 1770 y 1776. Por la información que aporta la documentación, procedente de los registros de la aduana del puerto de Santa Cruz, sabemos que la compañía abastecía las tiendas de Santa Cruz y del resto de la isla de diversos productos de mercería ${ }^{37}$ y los intercambios se establecían con determinados puertos internacionales como los de Génova, Falmuth o Londres, así como con la Península Ibérica a través de Cádiz ${ }^{38}$.

En este tiempo la empresa debió alcanzar una cierta entidad en el entorno de la ciudad portuaria, ya que sus almacenes no sólo guardaban los géneros habituales antes señalados, sino que también conservaban en sus depósitos el jabón del surtimiento de los estanquillos del público de la isla, y para poder cumplir con la reglamentación establecida tuvieron que hipotecar una bodega que poseían en Lanzarote ${ }^{39}$.

La estabilidad que habían aportado los socios y concuñados a la empresa de comercio se vio truncada el 24 de junio de 1776 con el fallecimiento de D. Antonio Bini a la edad de 45 ańos, de manera repentina, ya que no pudo hacer su testamento y sólo recibió la extremaunción.

La muerte de uno de los participantes entrañaba las necesarias modificaciones, que se iniciaron con la disolución de la compañía que compartían Bini y Dugi, sin que esto supusiera la desaparición de la alianza que habían forjado. De manera que, el 13 de julio de 1776, a un mes escaso de la muerte de D. Antonio Bini, D. Francisco Dugi fundaba una nueva empresa tomando como socia a su cuñada Dña. Juana Ryan, viuda de Bini. La defunción del esposo, sin descendencia, permitió a Dńa. Juana actuar con un cierto margen de libertad. La nueva sociedad fue registrada bajo el nombre de D. Francisco Dugi y Compañía aunque la mitad del capital aportado a la actual empresa correspondía a Dña. Juana, por expreso deseo de su esposo ${ }^{40} ; \sin$ embargo, la denominación de la sociedad no visibiliza la presencia de la viuda de Bini.

Y es que este tipo de prácticas, habituales en el mundo de los negocios, han mantenido a las mujeres en el lado oscuro de los registros profesionales.

Cabe ańadir que en la nueva etapa emprendida por Dugi, de la mano de su cuñada, lograron conservar los éxitos empresariales del pasado, puesto que, según los registros de mercancías llegadas a sus despachos, el volumen del negocio no decreció.

Además, hay que destacar la incorporación de un nuevo miembro de la familia a la actividad mercantil de la empresa. D. Jacome Busse, casado con Dńa.

${ }^{37}$ Entre los productos que figuraban en el despacho de Antonio Bini destacan los tejidos: lamparilla, anascote, camelote, bayeta o sempiterno, unido al paño denominado ordinario. También surtía a la población santacrucera de otros productos como medias, gorros y quincallería diversa (AHPSCT, H-02-11, fols. 9r., 24v., 44v., 1770).

${ }^{38}$ AHPSCT, H-02-11, fols. 9r., 24v., 44v., 1770.

39 Pérez Álvarez, Ana Rosa: Objetos de adorno personal, vida cotidiana y ritual funerario procedentes de yacimientos de Arqueología Histórica. La Iglesia de la Concepción de Santa Cruz de Tenerife, 2016. Tesis doctoral dirigida por la Dra. D. ${ }^{a}$ Matilde Arnay de la Rosa. Departamento de Geografía de Historia de la Facultad de Humanidades de la Universidad de La Laguna, pp. 850-853.

${ }^{40}$ Que manifestó su deseo de traspasar los bienes a su esposa y porque era lo que le tocaba por los gananciales del matrimonio (AHPSCT, P.N. 1.609, fols. 124r.-133r., 1776). 
Tomasa Ryan, quien actuó como representante de la firma de D. Francisco Dugi y Compañia, al menos en 1776, cuando fue enviado por el fundador de la entidad a cobrar unas deudas que tenían en las islas de Lanzarote y Fuerteventura. Al hallarnos en un año de tránsito, 1776, los pagos correspondían tanto a la etapa anterior como a la más reciente ${ }^{41}$.

Parece evidente que las mujeres se visibilizaban en el escenario comercial en el momento en que desaparecía el cabeza de familia. En este sentido, el estado de viudedad permitía a las féminas asumir públicamente los compromisos que conllevaba el negocio familiar. En muchas ocasiones acuden a los juzgados a reclamar las deudas de las que sus cónyuges eran acreedores ${ }^{42}$.

Esta actitud asumida por las mujeres va en contra de su supuesta pasividad en el terreno laboral; así lo afirma Juan Manuel Bartolomé refiriéndose a las comerciantes leonesas, ya que una vez que enviudaban asumían las obligaciones inherentes al negocio que regentaban sus maridos ${ }^{43}$. En el mismo sentido se expresa Marcela Aguirrezabala aludiendo a las viudas del Río de la Plata, porque éstas aparecían con frecuencia como protagonistas de las transacciones comerciales, probablemente al sentirse libres de la tutela marital ${ }^{44}$.

Ésta fue una realidad que también vivieron las mujeres de la familia Ryan. Ya hemos visto como Dña. Juana, viuda de Bini, comparte las responsabilidades del negocio con su cuñado sólo después del fallecimiento de su marido, visibilizándose de esta manera su «actividad profesional». En cualquier caso, en la misma situación se había visto su madre, Dńa. Bárbara, tras la muerte de su esposo, pues se convierte en la cabeza visible del clan teniendo que asumir cometidos de carácter económico. En la escritura de obligación y fianza que firman D. Francisco Dugi y Dña. Juana Ryan para hipotecar la bodega que poseen en Lanzarote, sale como fiadora Dńa. Bárbara Ligero, quien declaraba «no estar sugeta a ningún estado, tutela ni curaduría ${ }^{45}$. La fianza comportaba hipotecar la casa, alta y sobrada, en la que residía en la calle de la Cruz Verde en Santa Cruz ${ }^{46}$.

Parece fuera de toda duda que muchas señoras quedaron abocadas a desarrollar diversas actividades comerciales, y es que, como señala Francisco Ramiro, en su estudio sobre las mujeres en el ámbito aragonés, las esposas de los comerciantes y

41 AHPSCT, P.N. 1294, fols. 105r.-110r., 1780.

42 Borchart de Moreno, Christiana: «La imbecilidad y el coraje. La participación femenina en la economía colonial (Quito, 1780-1830), Revista Complutense de Historia de América, n. ${ }^{\circ} 17$ (1991), p. 174.

43 Bartolomé Bartolomé, Juan Manuel: opus cit., 2015, p. 498.

44 Aguirrezabala, Marcela: opus cit., 2008, pp. 147-148.

45 AHPSCT. P.N. 1609, fol. 127r., 1776.

46 En el testamento declara que la heredó de sus padres, aunque en esta escritura reconoce que la fabricó su marido durante el matrimonio y durante su viudedad le agregó los sitios que tiene a su espalda, ascendiendo la cifra total de gastos a más de 6000 pesos (AHPSCT, P.N. 1292, fols. 244v.-249v., 1776; y P.N. 1609, fols. 124r.-133r., 1776). 
mercaderes eran las naturales compañeras y ayudantes de sus maridos, así como sus sustitutas en las frecuentes ausencias por sus viajes o tras el fallecimiento de éstos ${ }^{47}$.

La confianza que los comerciantes varones depositaban en sus esposas se fue fraguando en los ańos compartidos durante el matrimonio. La vida de muchas de estas mujeres había estado ligada a las actividades mercantiles desde su infancia a través de los negocios de sus padres; no eran ajenas, por tanto, a los requerimientos de la profesión. En cualquier caso, el aprendizaje en los negocios no estaba sujeto a una formación reglada; bien al contrario, podría definirse como un aprendizaje silencioso, como lo denomina Juanjo Romero ${ }^{48}$, basado en la experiencia que las mujeres iban adquiriendo primero junto a los padres y posteriormente al lado a sus maridos. En opinión de Mercedes Gamero hubiera sido suicida no preparar a las mujeres para tomar las riendas de los negocios en caso de necesidad ${ }^{49}$.

Todo ello hizo que la seguridad ganada en el matrimonio se reflejara en las últimas voluntades de los esposos declarando a sus cónyuges administradoras y albaceas de sus bienes. Una muestra de este proceder se evidencia en el testamento de D. Jacome Busse, en el que dispone que su esposa, Dńa. Tomasa Ryan, se encargue de liquidar las cuentas que le han quedado pendientes con la compañía de sus concuñados; además, es nombrada tutora adbona y curadora adlister de todos sus hijos y declara que la releva

... de toda fianza atento a la grande confianza que tengo de ella por sus sircunstancias y buena conducta, a mas del particular amor que le tiene a dichos nuestros hijos, y el conosimiento que tiene del estado de mi casa, negocios y dependencias... ${ }^{50}$.

Es evidente que las mujeres de los comerciantes terminaron afianzándose en el mundo de los negocios: no sólo fueron consideradas aptas para su dedicación «natural» de madres y esposas, sino que acabaron colaborando en pie de igualdad con sus esposos en los negocios que éstos emprendían, como sugiere D. Jacome Busse en su testamento.

\section{CONCLUSIONES}

Como hemos visto en las líneas anteriores, el trabajo de las mujeres en el mundo comercial del Antiguo Régimen se ha visibilizado de dos formas completamente diferentes, dependiendo del nivel económico de las transacciones realizadas.

47 Ramiro Moya, Francisco: opus cit., 2012, p. 213.

${ }^{48}$ Romero Marín, Juanjo: «La maestría silenciosa: maestras artesanas en la Barcelona de la primera mitad del siglo XIX», Arenal. Revista de Historia de las Mujeres, vol. 4, n. ${ }^{\circ}$ 2, (1997), p. 293.

${ }^{49}$ Gamero Rojas, Mercedes: "La mujer en el mundo de los negocios en la Sevilla del siglo xviri», en Núñez Roldán, Francisco y Gamero Rojas, Mercedes (coords.): Entre lo real y lo imaginario. Estudios de Historia Moderna en Homenaje al profesor León Carlos Álvarez Santalo, Sevilla, 2014, p. 203.

50 AHPSCT, P.N. 1.294, fols. 105r.-110r., 1780. 
Por un lado tenemos a las vendedoras en tiendas o ambulantes, que en Canarias se conocían como "vendederas», situadas en el nivel más bajo de las ventas de productos, para cuya actividad laboral no se necesitaba ninguna inversión económica, se veían por las calles realizando su trabajo y se mencionan abiertamente en los documentos. En el otro extremo tenemos a las «mercaderas», cuya actividad quedaba eclipsada por la de sus padres, maridos o hermanos, que eran los que "parecía» que realizaban todos los negocios, pero una lectura detallada y profunda de los documentos originales nos permite ver como ellas también desarrollaban transacciones comerciales en la ausencia de los varones de la familia, por sus viajes o por sus fallecimientos.

Este artículo es el primer paso en la investigación que estamos desarrollando sobre las mujeres comerciantes o «mercaderas», con la que queremos devolverles a ellas el verdadero papel que ocuparon en la Historia Económica de Canarias durante el Antiguo Régimen, y que quedó difuminado tras los hombres y el paso del tiempo.

RECIBIDO: 22-03-2018, ACEPTADO: 10-04-2018 